\title{
Food Quality Protection Act launches search for pest management alternatives
}

Robert A. Van Steenwyk

Frank G. Zalom

Insecticides have long been important tools for California farmers to combat agricultural pests. By 1995, organophosphate (OP) insecticides such as chlorpyrifos, azinphos-methyl, methamidophos, phosmet and diazinon accounted for an estimated $34 \%$ of worldwide insecticide sales, and they are widely credited with allowing large yield increases in commercial agriculture. The U.S. Food Quality Protection Act (FQPA), signed into law in 1996, established a new human health-based standard that "reasonable certainty of no harm will result from aggregate exposure to the pesticide chemical residue." When the FQPA was passed, 49 OP pesticides were registered for use in pest control in the United States; since then, many uses have been canceled and others are expected to be lost, with particular significance for California growers. A number of alternative pest-control products and strategies are available, with varying degrees of effectiveness and cost. Research and development of control measures to replace $O P$ insecticides must be pursued to maintain an economically viable state agricultural industry.

Tnsecticides have long been important Itools for California farmers to combat agricultural pests. However, the types of insecticide products have changed substantially over time in response to the availability of new chemicals, the development of pest resistance and regulations addressing environmental and health concerns. Prior to World War II, most insecticides used by farmers were inorganic products such as calcium arsenate, lead arsenate and sulfur, or botanical insecticides such as pyrethrum

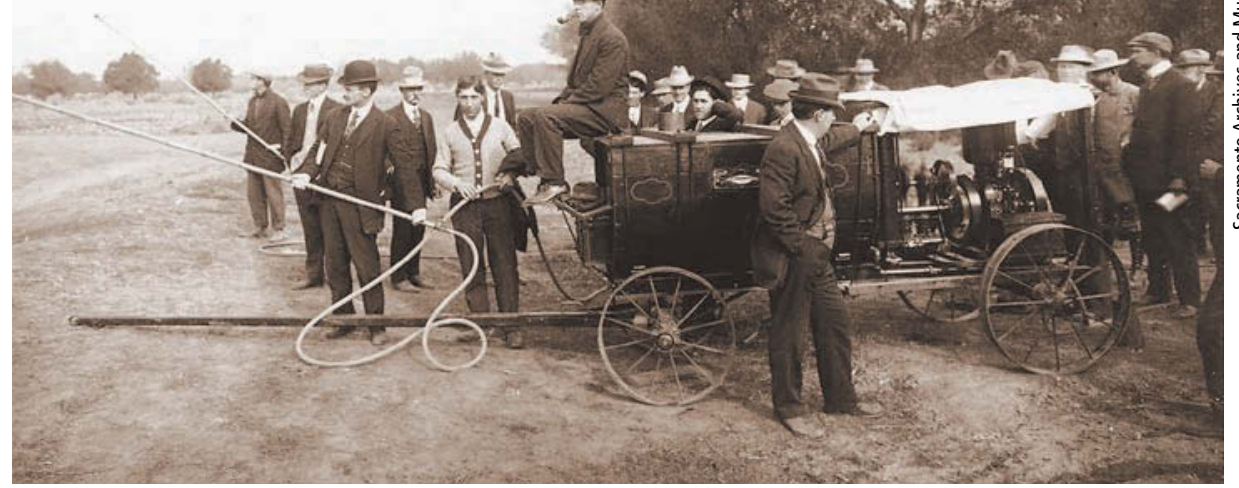

In 1910, Bliss S. Brown, professor of botany and horticulture at the University Farm (later UC Davis), demonstrated a spray pump to a pomology class in Davis. Nearly a century later, UC scientists are researching alternatives to insecticides whose uses are being restricted under the Food Quality Protection Act.

and nicotine. With the exception of sulfur and pyrethrum, various synthetic organic insecticides have replaced the inorganic and botanical insecticides.

In the turbulent years immediately preceding and during World War II, supplies of the botanical products became limited and an effort was made to identify, synthesize and manufacture replacement insecticides to protect military personnel from insect-borne diseases and crops from insect pests. Scientists in England and France identified the insecticidal properties of the precursors to organochlorine and cylclodiene insecticides in 1939. Because their acute mammalian toxicity was low and their spectrum of activity against insects was high, the organochlorine insecticides - which include products such as DDT, dieldrin and aldrin - were immediately useful in controlling insect vectors of diseases (especially typhus and malaria) during World War II. Following World War II, organochlorine and cylclodiene insecticides became widely used in agriculture.

Despite their effectiveness, the organochlorine and cylclodiene insecticides were persistent in the environment, and their effects on nontarget species resulted in outbreaks of a number of secondary pests or the rapid resurgence of the target pest through the suppression of beneficial insects (Stern et al. 1959). In addition, organochlorine and cylclodiene insecticides were widely implicated in adverse effects upon wildlife (Carson 1962). As a result, most of these products were eventually banned for use.

German scientists identified the insecticidal activity of organophosphorus compounds the 1930s, but their chemistry was primarily exploited for possible use as chemical warfare agents. After the war, the organophosphate (OP) compounds were developed as insecticides. The OP insecticides are acutely toxic to mammals, exhibit cholinesterase inhibition, have a broad spectrum of activity against insect pests and have relatively short environmental persisthe environment than the chlorinated hydrocarbons. By 1995, OP insecticides accounted for an estimated $34 \%$ of worldwide insecticide sales (Casida and Quistad 1998). Some popular products include chlorpyrifos (Lorsban), azinphos-methyl (Guthion) and phosmet (Imidan). They are widely credited with allowing large yield increases in commercial agriculture.

In the late 1940s, methyl carbamates were developed as insecticides. The methyl carbamates exhibited cholinesterase-inhibition activity similar to that of the OP insecticides. Like tence. They are much less persistent in 


\section{"Food quality" is a misnomer, since FQPA considers all potential pathways by which people may be exposed to pesticides.}

the OP insecticides, they have a broad spectrum of activity and are toxic to many nontarget species, particularly beneficial insects as well as wildlife. They tend to degrade relatively rapidly in the environment, except for aldicarb, which became a problem when it was shown to leach in sandy soils and enter groundwater.

\section{The Food Quality Protection Act}

As a group, both the OP and methyl carbamate insecticides have continued to be widely used in California agriculture during the past half century. Growers favor the use of these synthetic organic pesticides because they are effective, relatively inexpensive and have a broad spectrum of activity. Their widespread use, however, has also brought with it environmental and human health concerns, including: pesticide residues on food, particularly as they relate to infants, children and vulnerable groups; pesticide contamination of rivers and streams via runoff from treated fields and orchards; drinking water contamination from the infiltration of pesticides through the soil; and the destruction of wildlife such as birds of prey as well as the destruction of beneficial insects and mites.

These concerns have been addressed by a number of state and federal laws, including the Food Quality Protection Act (FQPA) and the Clean Water Act. The FQPA was unanimously passed by both houses of the U.S. Congress and signed into law by President Clinton on Aug. 3, 1996 (US EPA 1996). This piece of legislation has had, and will continue to have, a major impact on agricultural amended two previous laws: the Federal Insecticide, Fungicide and Rodenticide Act (FIFRA) and the Federal Food, Drug and Cosmetic Act (FFDCA). The FQPA established a new human health-based standard that "reasonable certainty of no harm will result from aggregate exposure to the pesticide chemical residue." In this respect, "food quality" is a misnomer, since the law considers all potential pathways by which people may be exposed to pesticides when establishing acceptable food residue limits.

Previously under FIFRA and FFDCA, pesticides were registered by the U.S. Environmental Protection Agency (EPA) with the intent to "prevent unreasonable adverse effects on human health or the environment" by establishing maximum permissible tolerances of a pesticide residue on food. An important feature of the FQPA is its special consideration of health effects on children and other vulnerable individuals. This additional emphasis in the FQPA reflects the pesticide use. The FQPA significantly

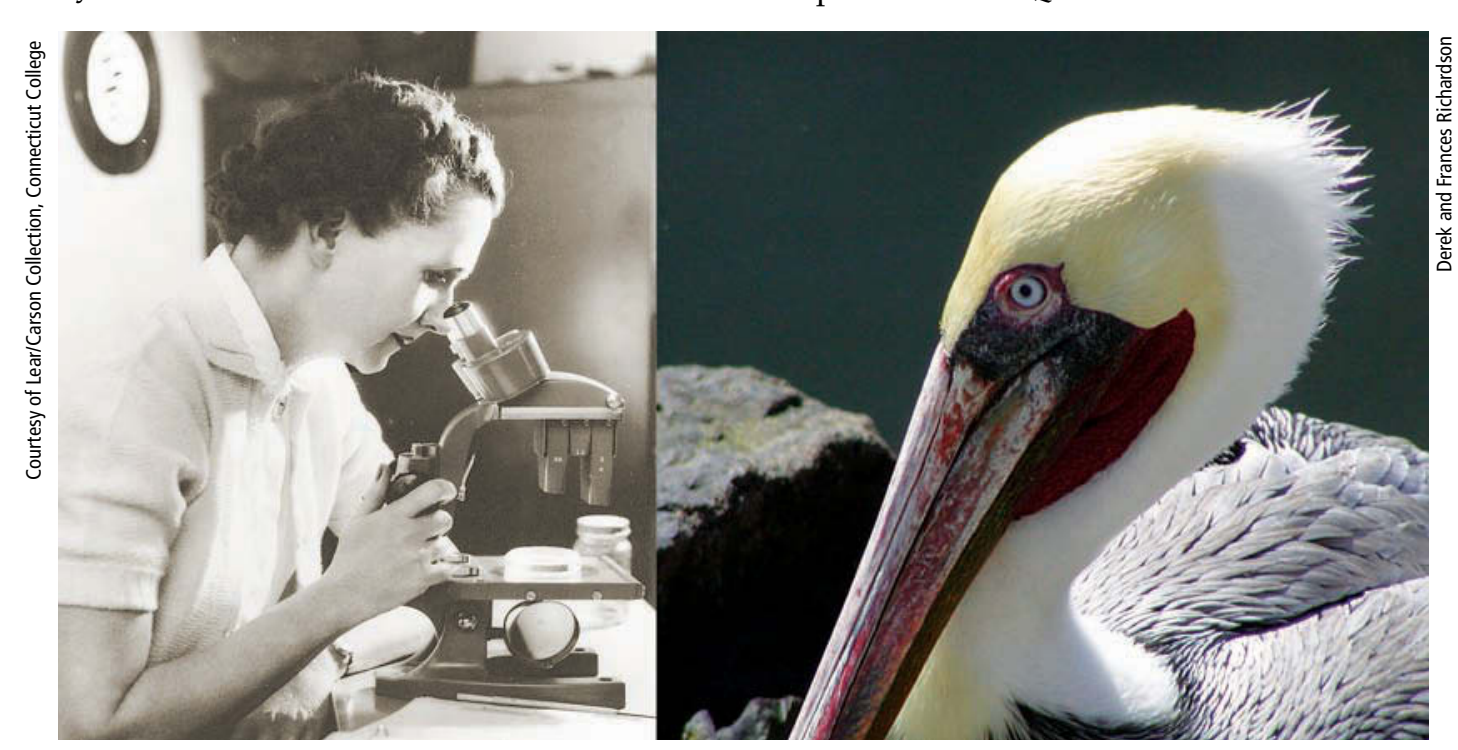

Rachel Carson (shown, left, in 1951 during her service as a U.S. Fish and Wildlife Service scientist) warned of the environmental impacts of certain pesticides in her 1962 book, Silent Spring. Right, brown pelican populations severely declined during the mid-20th century because of exposure to DDT, which thinned their egg shells; the insecticide was banned for general use in 1972.

8 CALIFORNIA AGRICULTURE, VOLUME 59, NUMBER 1 findings of a National Research Council (1993) report, Pesticides in the Diets of Infants and Children, which proposed that differences exist among segments of the population in terms of impacts from pesticide exposure.

The FQPA requires the EPA to reassess all pesticide tolerances. The tolerance reassessments must consider the cumulative effects of the aggregate exposure from all sources (dietary, drinking water and residential) of pesticides with a common mechanism of toxicity. In addition, the tolerance may be reduced 10-fold as a safety factor to provide additional protection for infants and children. This 10 -fold safety factor need not be imposed when reliable information indicates that no harm will result to infants and children. The law calls for the tolerance reassessments to be completed within 10 years (in two 3-year increments followed by a 4-year increment), with priority given to pesticides that may pose the greatest risk to public health. The reregistration of all pesticides registered before 1984 under FIFRA will incorporate the new healthbased standard of the FQPA.

\section{Minor-use pesticides}

In addition to establishing a new health-based standard of no harm, the FQPA also provides for the expedited registration review of "reduced risk" pesticides. A reduced-risk pesticide has lower human or nontarget organism toxicity, lower potential for environmental contamination and greater potential for increasing the adoption of integrated pest management (IPM) practices as compared to conventional insecticides. After a pesticide receives a reduced-risk classification, the EPA must make registration review decisions within 12 months, considerably faster than for pesticides that do not receive such designation.

The act also offers economic incentives to pesticide registrants (usually the manufacturer) who register "specialty" or "minor use" pesticides. Minor uses are registrations for crops with 


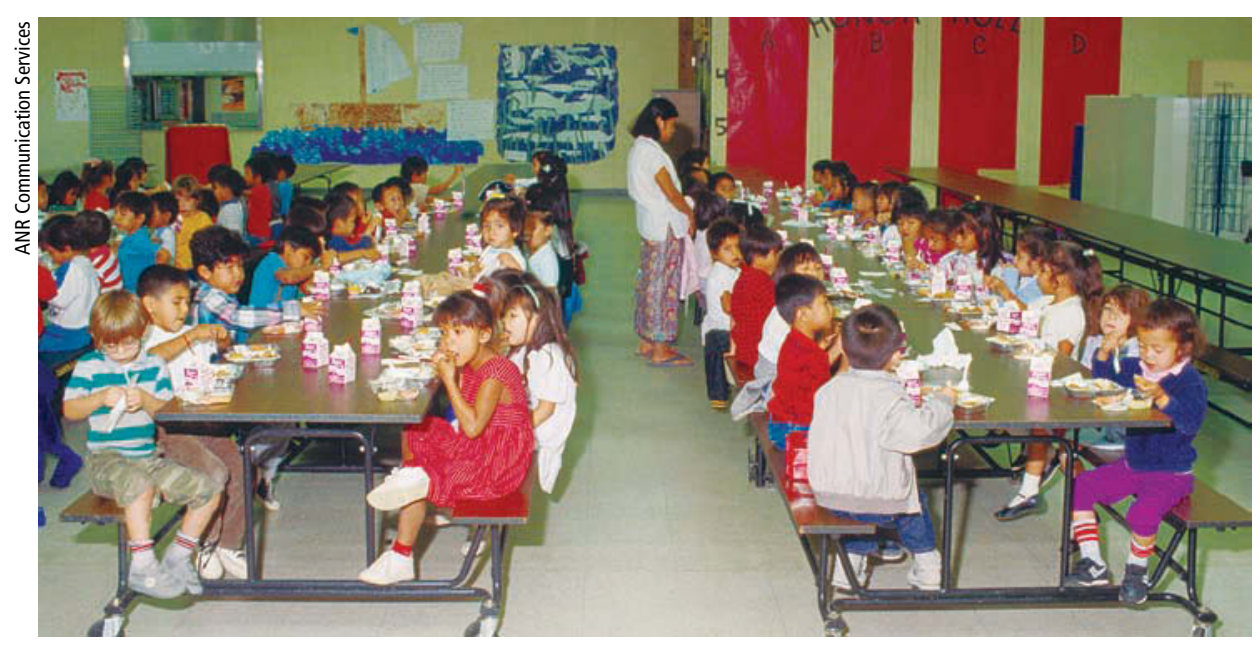

The Food Quality Protection Act reflects findings of a 1993 National Research Council report, Pesticides in the Diets of Infants and Children. The law requires an additional 10-fold safety factor on some pesticide tolerances to provide additional protection for young people.

less than 300,000 acres in production, which the EPA administrator determines do not provide sufficient economic incentive to support registration and for which there are no effective pesticide alternatives, or uses for which the available alternatives pose greater human risks. A pesticide can also receive minoruse status if it significantly aids in resistance management or improves IPM systems. The incentives may include an additional year of exclusive data use, waivers of certain data requirements and expeditious review that could bring the product to market sooner.

California's diverse crop production includes many minor uses, and this has often resulted in fewer available pesticide options for fruit, nut and vegetable growers relative to those for the producers of larger acreage field crops such as corn, cotton and soybeans. The FQPA also set a goal for the EPA to review all pesticide registrations on a 15 -year cycle to ensure that all pesticides meet updated safety standards. Additional provisions of the FQPA are somewhat less likely to affect California agriculture.

\section{Focus on public health risks}

The reassessment of all pesticide tolerances by the EPA presents a daunting task for that agency, since there were more than 9,700 in 1996 when the law was enacted. A pesticide tolerance is the amount of allowable pesticide residue on an individual commodity at harvest, and each pesticide (active ingredient) may have many individual tolerances. Therefore, the EPA is giving priority to pesticides that may pose the greatest risk to public health, first focusing on the reassessment of OP and methyl carbamate insecticides.

The OP insecticides bind to the enzyme acetylcholinesterase in the central and peripheral nervous system. This deactivates the acetylcholinesterase, resulting in repeated, uncontrolled stimulation (firing) at the nerve junctions. The EPA has tentatively considered the OP insecticides to act through a common mechanism of toxicity. While dietary exposure to a particular OP may be low, the simultaneous exposure to multiple OP insecticides may result in some segments of the population exceeding acceptable daily allowances (Byrd 1997). The implementation and ramifications of the OP insecticides having a common mode of toxicity has not been clarified at this point.
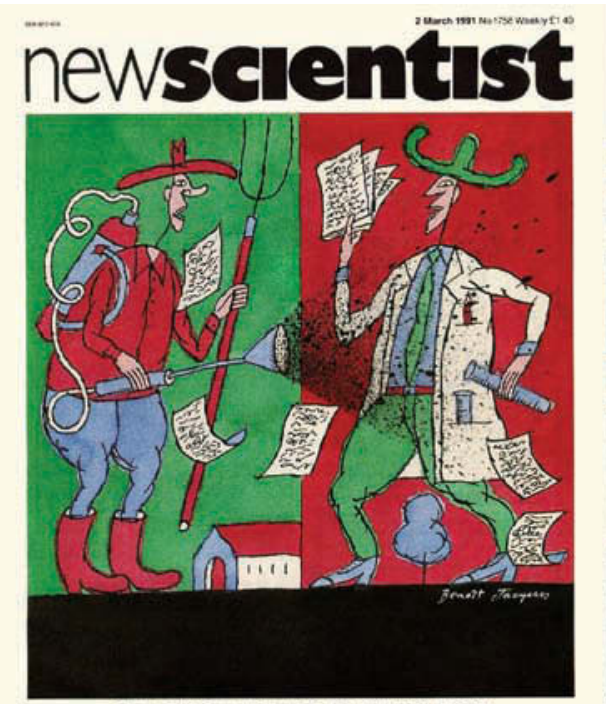

CALIFORNIA'S WAR ON PESTICIDES Big bang in trouble
Fishing fleets alter evolution
Pricing cars off city streetr

Pesticide regulation has long been controversial in California (March 1991 cover shown).
When the FQPA was passed in 1996, 49 OP pesticides were registered for use in pest control in the United States. When the EPA released the Revised OP Cumulative Risk Assessment (2002), 14 pesticides had been canceled or proposed for cancellation and 28 others had partial use bans. Voluntary and mandated cancellation or restriction on a number of uses for $\mathrm{OP}$ insecticides - such as azinphos-methyl, chlorpyrifos, ethion, ethyl parathion and methyl parathion - has had particular significance for California growers.

For example, the EPA accepted voluntary label restrictions on azinphosmethyl, which included reducing the maximum seasonal rate in pome fruit, lengthening the intervals between last application and harvest, and increasing the intervals between an application and worker reentry. Restrictions on chlorpyrifos included canceling inseason uses on apples and grapes, reducing the maximum number of applications in alfalfa, and increasing the intervals between an application and worker reentry for citrus, nuts and stone fruit. Actions on methyl parathion included lengthening the interval between an application and worker reentry, and canceling most food crop uses (particularly for commodities consumed by children) and all ornamental and public health uses. All registrations have been canceled for both ethyl parathion and

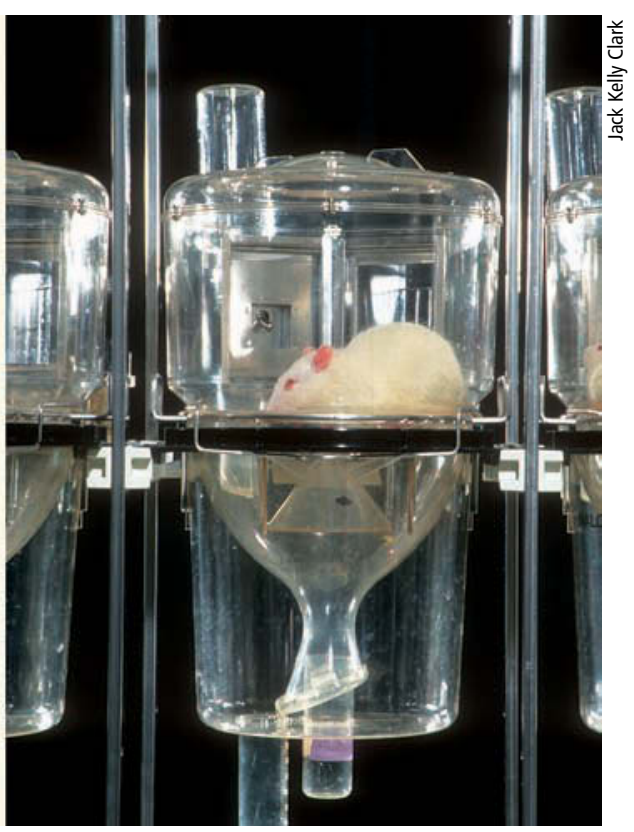

Toxicological research on animals helps to inform pesticide regulatory decisions. 


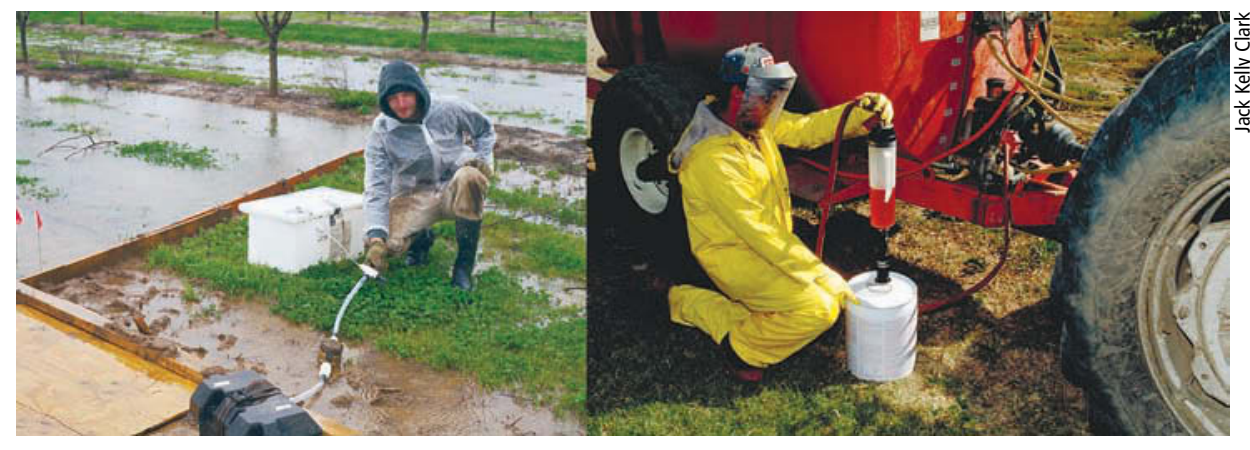

Left, former UC Davis graduate student Till Angermann monitors an autosampler to test the effects of best management practices for reducing dormant-season organophosphate runoff from orchard crops. Right, closed loading systems are important when handling certain organophosphate insecticides.

ethion. In addition, the EPA has accepted voluntary action on phosmet including the cancellation of its uses for domestic pets, household ornamentals and fruit trees, and diazinon is no longer registered for urban uses. It is anticipated that further restrictions on $\mathrm{OP}$ insecticides including product cancellations will be imposed in the future.

\section{Pest control alternatives}

The regulatory focus of the FQPA is the reduction of the human health effects of pesticides, but it is understood that economic and environmental consequences will also result from its implementation. The quantitative and qualitative impacts of the modification or cancellation of OP insecticide use depends on the availability and adoption of effective alternative control measures. A study of the 13 top-valued California crops having a total market value of about $\$ 10$ billion (Metcalfe et al. 2002) estimated that a total ban of OP insecticides on these crops would result in a loss of over $\$ 203$ million for growers and consumers.

Qualitative effects include changes to IPM programs that use OP insecticides therapeutically, based on pest monitoring and established treatment thresholds. Other qualitative effects include: positive or negative impacts on beneficial arthropods, depending on the specificity and other properties of the alternative control measure; reduced ability to practice resistance management through the elimination of alternative modes of toxification and the suppression of detoxification mechanisms; and unintended negative consequences to nontarget organisms.

In addition, overall pesticide use may increase if the alternatives are not as ef- fective as the OP insecticide and multiple applications of the alternative insecticide are required to achieve adequate pest control. Overall pesticide use may also increase if the alternative insecticide is highly pest-specific, so that different insecticides must be used for the control of a pest complex that could previously be controlled with a single OP insecticide.

The research and development of control measures to replace OP insecticides must be pursued to maintain an economically viable agricultural industry in California. Some pest control measures are becoming widely adopted as OP uses are lost, most notably the substitution of chloronicotinyl (neonicotinoid) and synthetic pyrethroid insecticides. Further restrictions on the availability and uses of OP insecticides have created market opportunities for new and novel pesticides, and some of these have found significant market niches. Nonchemical approaches, perhaps thought to be less effective or too costly in the past, are becoming preferred choices for some growers. For example, while still a small percentage of total U.S. and California production, the organic industry has experienced tremendous growth in recent years.

The articles in this issue of California Agriculture present pest management measures that can be used singularly or in an integrated manner as OP replacement strategies. They include: other synthetic insecticides that already have many labeled uses (see page 11); newly registered and novel synthetic insecticides (see page 29); natural and biological toxins that are registered or exempt from tolerances, including genetically modified crop plants (see page 35); pheromone mating disruption and other semiochemical approaches (see page
16); and biological and cultural control measures (see page 23). The authors of these articles - many of whom provided the pest-management technical expertise for a California Department of Food and Agriculture (CDFA) evaluation on the economic importance of OP insecticides in California agriculture (Metcalfe et al. 2002) — broadly review the nature of these specific controls, their advantages and disadvantages compared to other management measures, current uses and prospects for future use.

R.A. Van Steenwyk is Cooperative Extension Entomologist, Department of Environmental Science, Policy, and Management, UC Berkeley; and F.G. Zalom is Entomologist, Agricultural Experiment Station, and Cooperative Extension Entomologist, Department of Entomology, UC Davis. We gratefully acknowledge the California Department of Food and Agriculture for financial support in the development of the base document, The Economic Importance of Organophosphates in California Agriculture (Metcalfe et al. 2002), and in publication of this special issue. We also thank the many UC Cooperative Extension Specialists and Farm Advisors who provided technical expertise in the development of alternative scenarios for the specific crops studied.

\section{References}

Byrd DM. 1997. Goodbye pesticides? The Food Quality Protection Act of 1996. Regulation 20(4):57-62.

Carson RL. 1962. Silent Spring. Boston: Houghton Mifflin. 378 p.

Casida J, Quistad G. 1998. Golden age of pesticide research: Past, present, or future? Ann Rev Entomol 43:1-16.

Metcalfe M, McWilliams B, Hueth R, et al. 2002. The Economic Impact of Organophosphates in California Agriculture. California Department of Food and Agriculture. Sacramento, CA. $41 \mathrm{p}+$ app. www.cdfa.ca.gov/ publications.htm

National Research Council. 1993. Pesticides in the Diets of Infants and Children. Washington, DC: Nat Acad Pr. 386 p.

Stern VM, Smith RF, van den Bosch R, Hagen KS. 1959. The integrated control concept. Hilgardia 29(2):81-101.

[US EPA] US Environmental Protection Agency. 1996. Food Quality Protection Act of 1996. Washington, DC. www.epa.gov/oppfead1/fqpa

US EPA. 2002. Revised OP Cumulative Risk Assessment. Washington, DC. www.epa.gov/ pesticides/cumulative 